\title{
Investigation of the Relationship between Inhaled Benzene, Toluene, Ethylbenzene, and Xylene Concentrations and the Urine Metabolites Levels in People Working at a Petrochemical Complex
}

\section{Davoud Shahmohammadi ${ }^{1}$, Sara Karimi Zeverdegani ${ }^{2, *}$}

${ }^{1}$ MSc Student, HSE Management, Department of Natural Resources and the Environment, Islamic Azad University, Sciences and Research Branch, Tehran, Iran

${ }^{2}$ Assistant Professor, Department of Occupational Health Engineering, School of Health, Isfahan University of Medical Sciences, Isfahan, Iran

* Corresponding Author: Sara Karimi Zeverdegani, Department of Occupational Health Engineering, School of Health, Isfahan University of Medical Sciences, Isfahan, Iran.Email: s_karimi@hlth.mui.ac.ir

\begin{abstract}
Received: $15 / 07 / 2018$

Accepted: 15/09/2018

How to Cite this Article:

Shahmohammadi D, Karimi

Zeverdegani S. Investigation of the Relationship between Inhaled Benzene, Toluene, Ethylbenzene, and Xylene Concentrations and the Urine Metabolites Levels in People Working at a Petrochemical Complex. J Occup Hyg Eng. 2018; 5(2): 46-54. DOI: 10.21859/johe-5.2.46

Background and Objective: Petrochemical industries are known as one of the most important sources of organic pollutants which endanger the workers' health. The aim of this study was to evaluate the relationship between inhaled Benzene, Toluene, Ethylbenzene, and Xylene (BTEX) concentrations and some urine metabolites of people working at a petrochemical complex.

Materials and Methods: This cross-sectional study was an analytical type with 60 inhalation air samples and biological samples. Sampling and decomposition of pollutants were carried out in accordance with 1501 and 2549 methods of National Institute for Occupational Safety and Health (NIOSH). The results then were compared with the Occupational Exposure Scale (OEL) and the proposed National Occupational Exposure Indicators (BEI) in Iran. Statistical analysis was performed in SPSS software (version 17).

Results: The results of the study showed that the mean concentration of Trans, Trans-muconic acid (TTMA) was $137 \mu \mathrm{g} / \mathrm{g}$ Creatinine. The concentrations of Hyporic acid, Phenylglyoxalic acid, and Methyl-hyporic acid were obtained as $0.577,0.066$, and $0.404 \mathrm{~g} / \mathrm{g}$ Creatinine, respectively. In addition, the mean concentration of benzene, toluene, ethylbenzene, o-, mxylene, and p-xylene were 3.818, 4.004, 3.357, 0.132, and $2.0159 \mathrm{ppm}$, respectively. The results also showed that toluene and benzene concentrations in 5 inhalable samples and Hyporic acid and TTMA in 10 urine samples were higher than the proposed limit.

Conclusion: The mean total concentration of inhaled BTEXs and the urine metabolites were lower than the acceptable range recommended by the country. There is a high correlation between measured pollutants in respiratory air and the concentration of urine metabolites. Therefore, it can be concluded that the chronic exposure to these pollutants leads to an increase in the excretion of urine metabolites. As well, the working conditions have detrimental effects on the health of people encountering with these organic compounds.
\end{abstract}

Keywords: Biological Monitoring; BTEXs; Occupational Exposure; Petrochemical 


\title{
بررسى ارتباط بين غلظت بنزن، تولوئن، اتيلبنزن و تزيلن استنشاقى با سطوح متابوليتهاى ادرارى مربوطه در افراد شاغل در يك مجتمع يتروشيمى
}

\author{
داوود شاهمحمدى'! سارا كريمى زوردگانى ז.**
}

' دانشجوى كارشناسى ارشد مديريت HSE، دانشكده منابع طبيعى و محيط زيست، دانشكاه آزاد اسلامى، واحد علوم و تحقيقات تهران، ايران

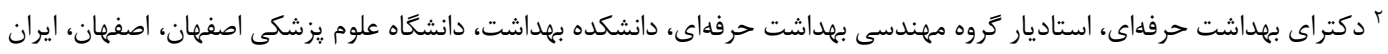

* *ويسنده مسئول: سارا كريمى زوردكانى، تروه مهندسى بهداشت حرفهاى، دانشكده بهداشت، دانشگاه علوم يزشكى اصفهان، ايران. ايميل: s_karimi@hlth.mui.ac.ir

\section{جكيده}

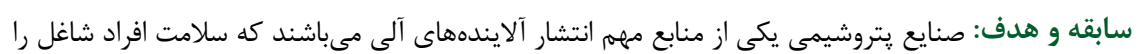

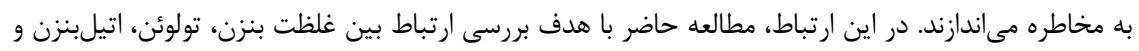

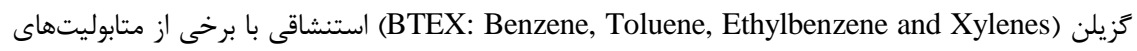
ادرارى در افراد شاغل در يك مجتمع پِتروشيمى انجام شد.

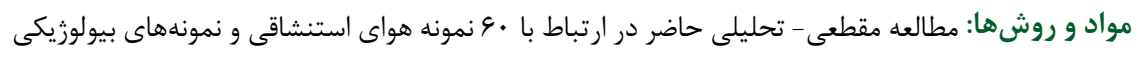

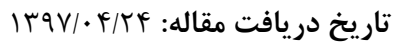

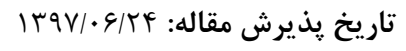
تمامى حقوق نشر براى دانشاءه علوم

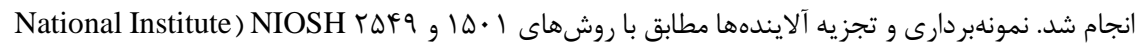
OEL: (انجام شد و نتايج با حدود مجاز مواجهه شأ شغلى (for Occupational Safety and Health BEI: Biological Exposure ( و شاخص هاى بيولوزيكى مواجها (Occupational Exposure Limit

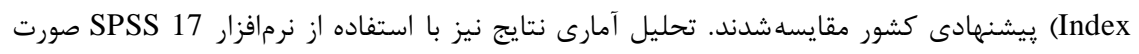

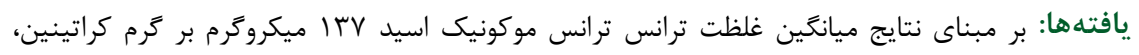

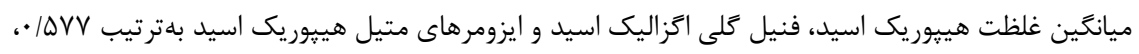

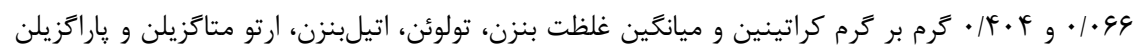

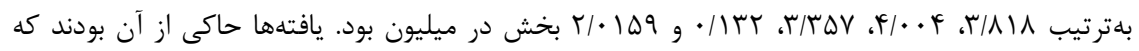

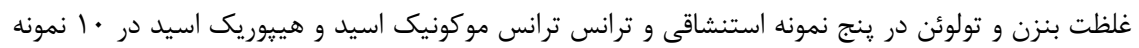

$$
\text { ادرارى بيشتر از حد مجاز بود. }
$$

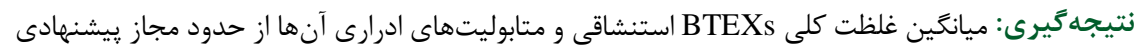

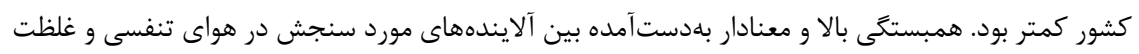

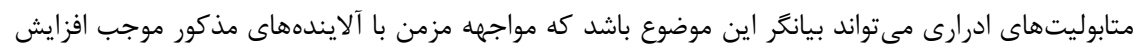

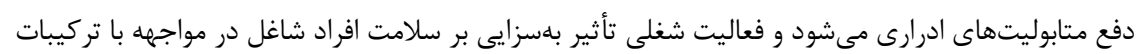
آلى فرار مورد مطالعه دارد.

وازَّان كليدى: پايش بيولوزيكى؛ يتروشيمى؛ مواجهه شغلى؛ BTEXs

وسيع مىشود كه باطور مستقيم و غيرمستقيم مىتواند اثراتى بر

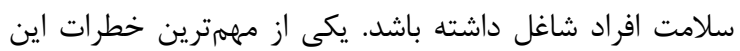
فرايند كه از هر سه جنبه بهداشت، ايمنى و محيط زيست داءت دائز

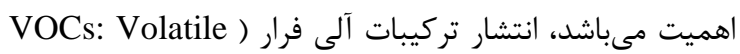

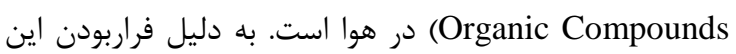

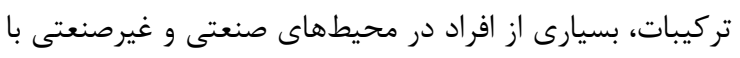

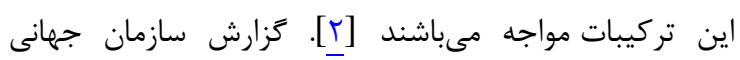

تركيبات BTEXs (بنزن، تولوئن، اتيلبنزن و 0، m p p

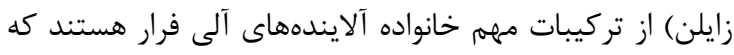

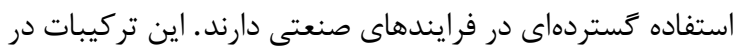

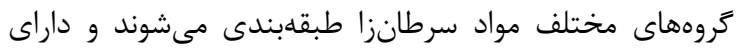

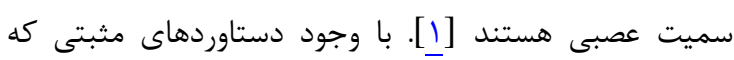

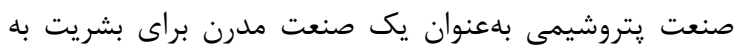

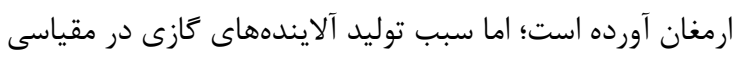


بنابراين، هدف از مطالعه حاضر اندازهيرى ميزان غلظت

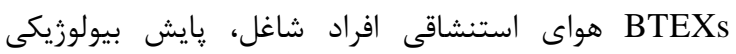

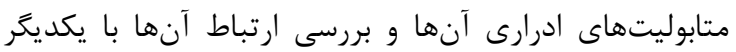

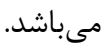

در مطالعه Kim و همكاران در مورد سنجش THCs

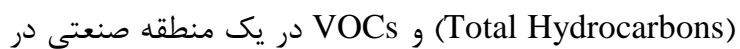
كره جنوبى مشاهده شد كه غلظت VOCs در مناطق صنعتى شهر Ulsan كره جنوبى حدود جهار برابر بيشتر از مناطق باييندست اين شهر است [111]

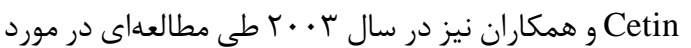

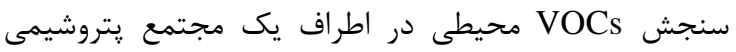

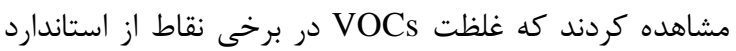

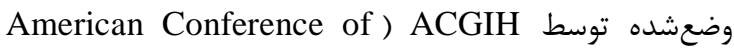
Governmental Industrial Hygienists

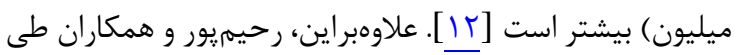

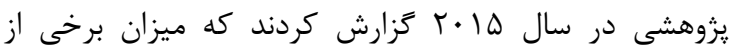

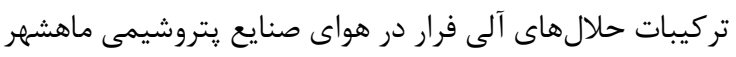

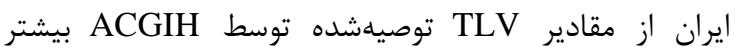
مىباشد [1 إن]

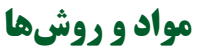

مطالعه توصيفى- تحليلى حاضر به روش مقطعى در يك ديك

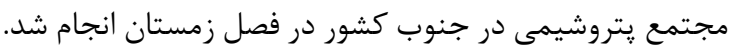

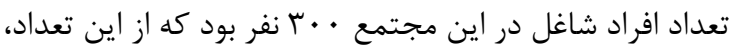

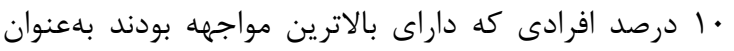

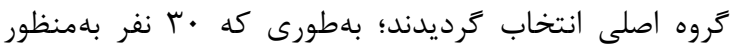

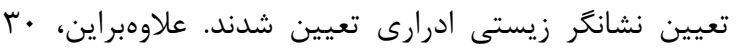

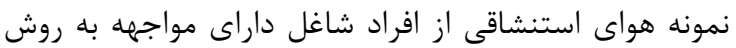
تسهيم و تصدفى ساده (Simple Random Sampling) كرفته شد. معيارهاى ورود به يزوهش عاده عبارت بودند ازئ رضايت

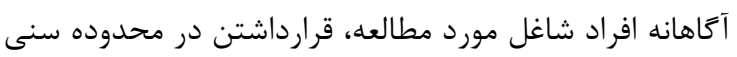

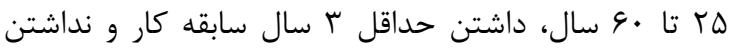

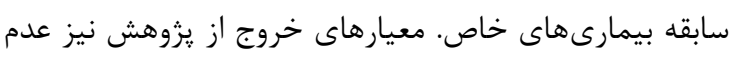

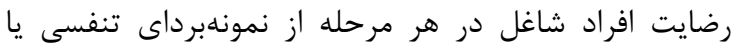

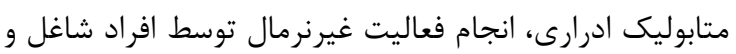

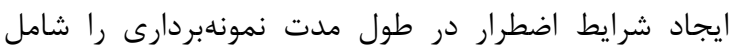

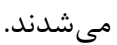
در ابتداى شيفت كارى در مورد روند و اهداف مطالعه براى

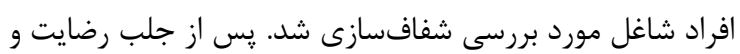

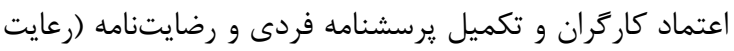

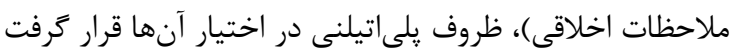

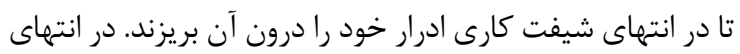

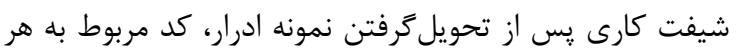

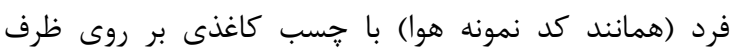

بهداشت WHO: World Health Organization) بيانكر آن

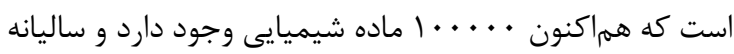

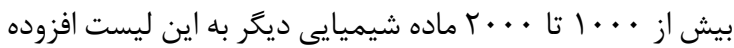
مىشود [ب]. از جمله مشاغلى كه بيشترين مواجهه را با اين دسته از

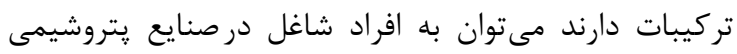

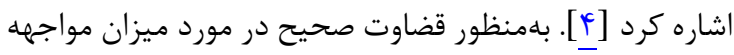

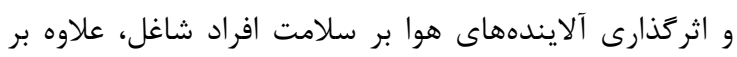

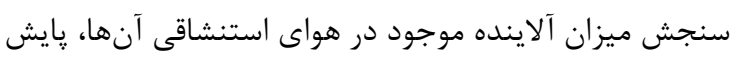

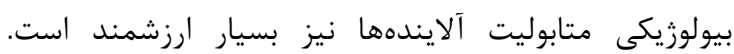

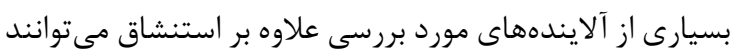

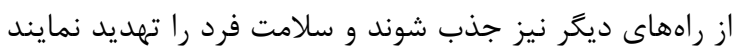

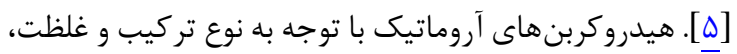

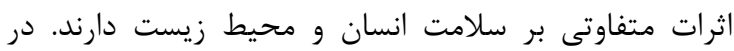

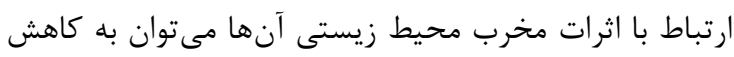

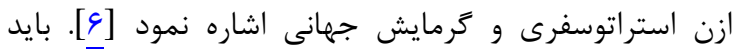

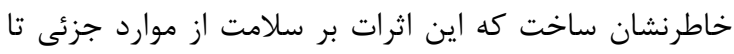

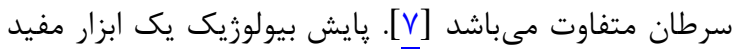

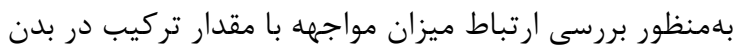

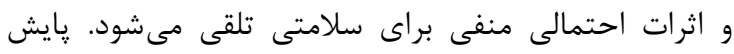

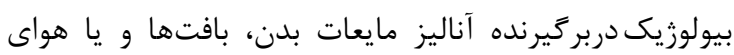

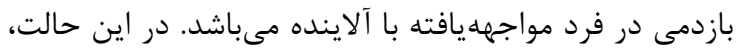

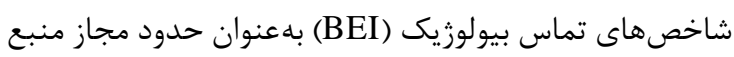

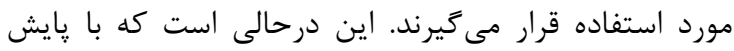

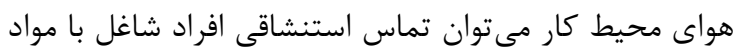

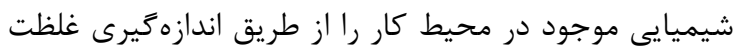

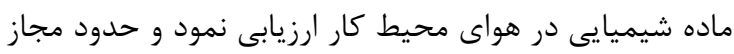

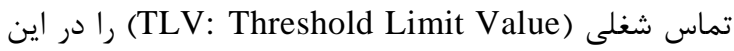

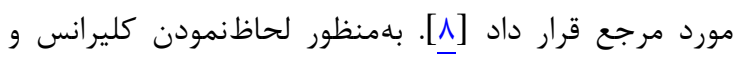

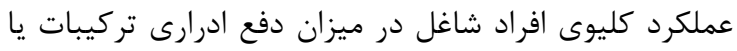

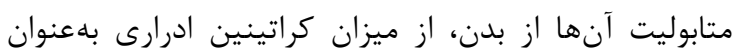

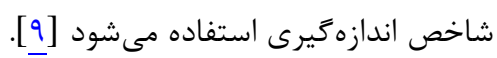

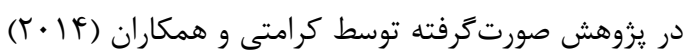

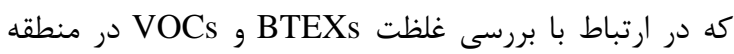

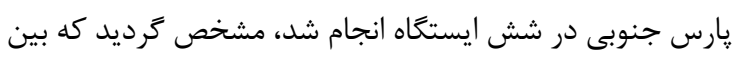

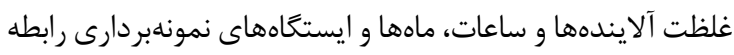
معنادارى وجود دارد و ميانكَين غلظت بنزن در ايستخاهها بالاتر

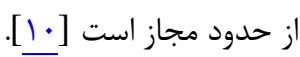

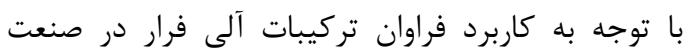

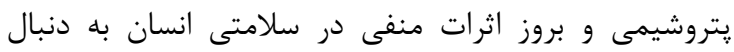

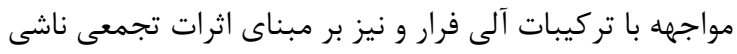

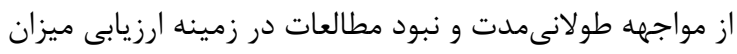

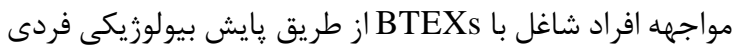

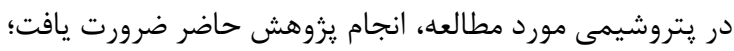


نمونهبردارى، شرايط نمونهبردارى از جمله نوع يمٍ، ساعت

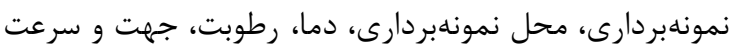

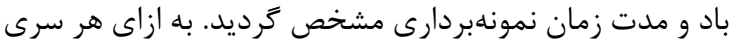

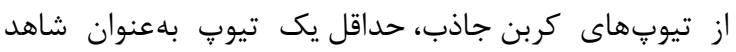

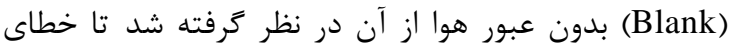

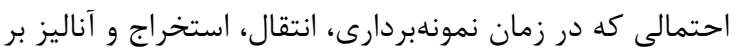

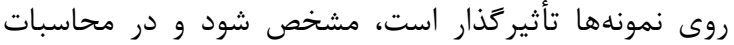

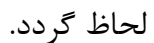

كارايى بازجذب لولههاى كربن فعال مطابق با روش انجام انجام (American Society for Testing and Materials) شد. در ادامه با استفاده از معادله ا، درصد بازجذب براى هر لوله كربن فعال محاسبه ترديد.

D.E $=100(S S-S B / S L)$

معادله

در اين معادله D.E= راندمان بازجذب زغال فعال؛

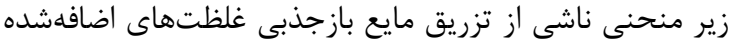

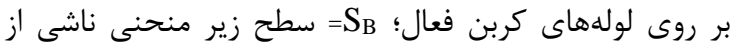

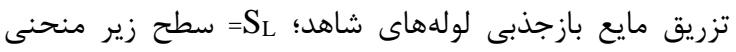

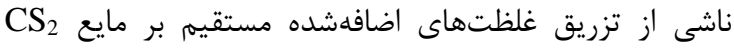
مىباشد. براى محاسبه غلظت واقعى آلاينده موجود در نمونه نيز از معادله r استفاده شد.

\section{$\mathrm{CA}=(\mathrm{CS}-\mathrm{CB}) / \mathrm{D} . \mathrm{E}$}

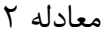

در اين معادله C= غلظت واقعى موجود در نمونه؛ غلظت اندازهَيرىشده نمونه؛ مى باشد.

بلهمنظور آناليز آمارى اطلاعات جمع آورىشده، بررسى ميزان

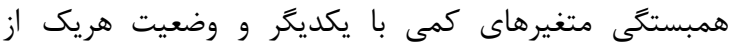

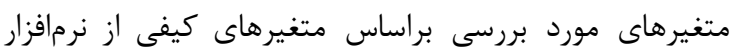

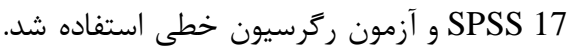

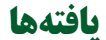

نتايج جمعيتشناختى افراد مورد مطالعه از نظر سن و سابقه كار و ميانگين غلظت BTEXs هواى تنفسى و متابوليتهاى

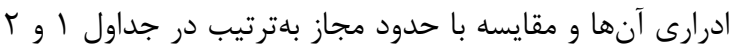

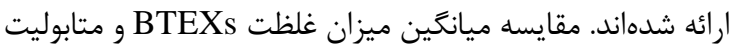

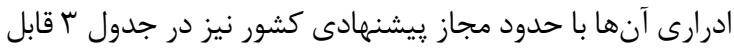
مشاهده مىباشد. براى تعيين رابطه يايش محيطى و بيولوزيكى تركيبات مورد

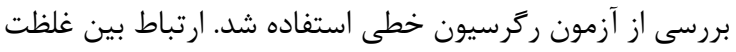

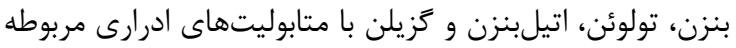

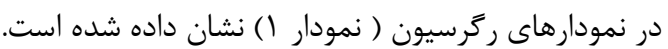

يلىاتيلنى جسبانده شد.

تعيين مقدار متابوليت اين آلايندهها به روش

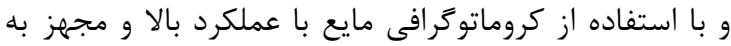

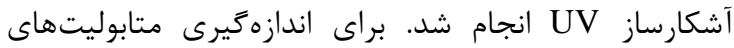
ادرارى تركيبات مورد نظر، نمونههاى ادرارى در یايان شيفت

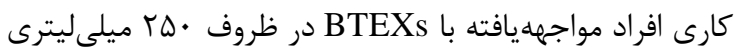

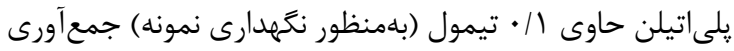

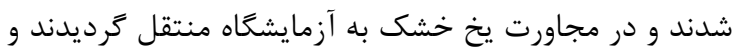

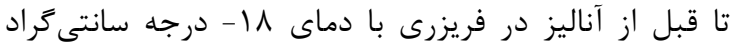

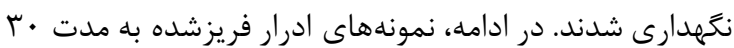

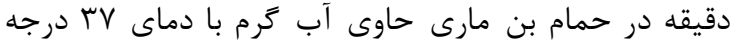

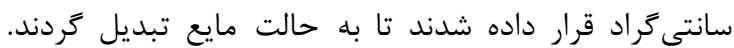

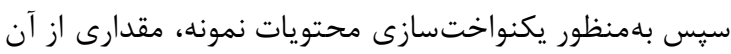

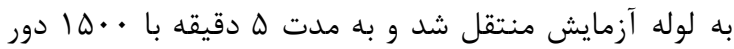

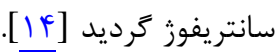
بامنظور تعيين غلظت Trans, Trans-Muconic ) TTMA SPE: Solid ) ادرارى از روش استخراج فاز جامد غلفين (Acid Phase Extraction

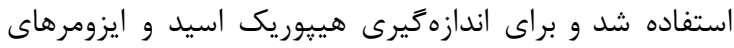
متيل هييوريك اسيد ادرارى مطابق با روش است استاندارد

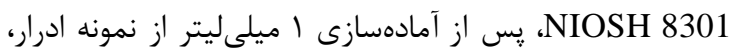

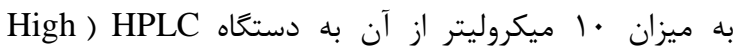
Performance Liquid Chromatograpy طول موج rQF نانومتر تزريق شد. علاوهبراين، بdمنظور اندازهخيرى فنل ادرارى مطابق با روش استاندارد 8305 NIOSH

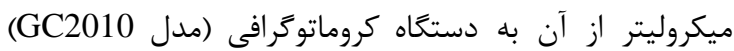
مجهز به آشكارساز Flame Ionization Detector) FID) و ستون • إ مترى مويين تزريق گرديد.

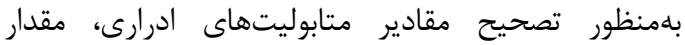

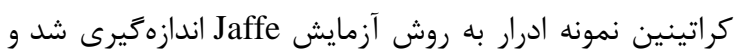

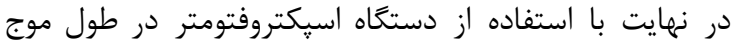
• نمونهبردارى از هواى منطقه تنفسى افراد شاغل مواجهه يافته

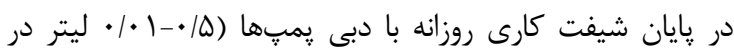

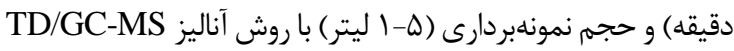

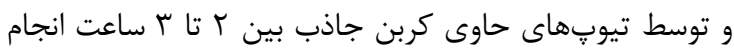

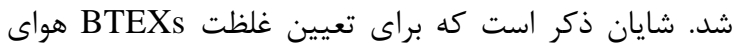

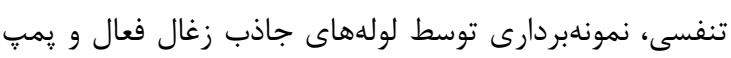

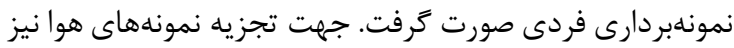

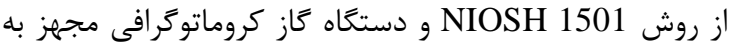

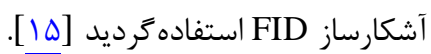

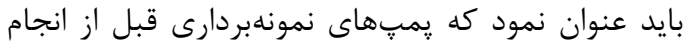

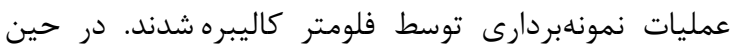


جدول ا: نتايججمعيتشناختى افرادموردمطالعه

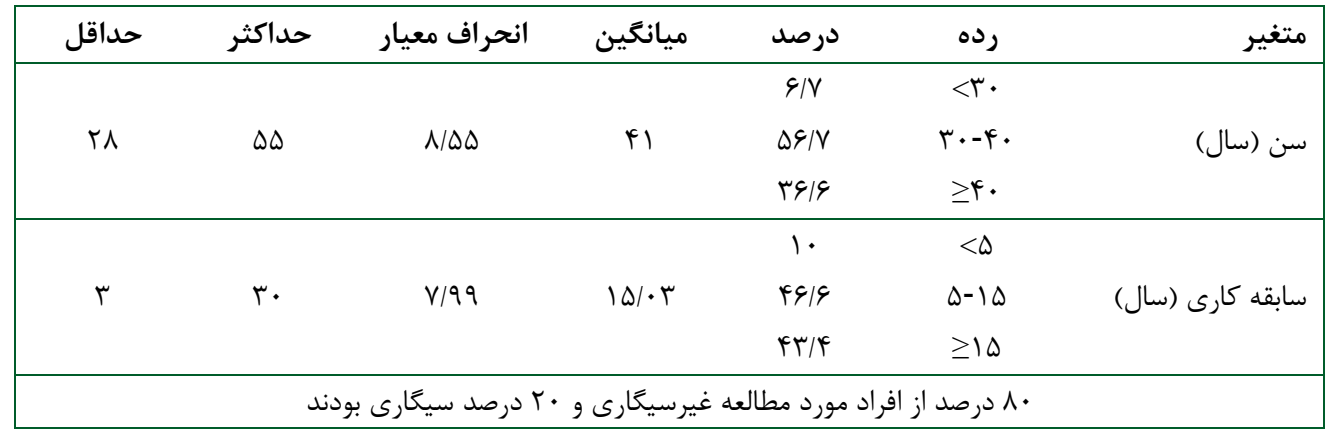

جدول r: نتايجاندازهيرى تركيبات BTEXs هواى تنفسى كارگران و متابوليتهاى ادرارى آنها

\begin{tabular}{|c|c|c|c|c|c|c|c|c|}
\hline انحراف معيار & ميانََين & حداكثر & حداقل & BEL & OEL & واحد & متغير & \\
\hline$\cdot / r \cdot 9$ & r & $1 / \cdot 11$ &.$/ .14$ & - & $\cdot 10$ & بخش در ميليون & بنزن & آلاينده \\
\hline $\mid r V / \cdot r \Delta$ & $r \mid 9 / 191$ & $111 / 9 \wedge \mathrm{V}$ & $1 \cdot 119$ & $\Delta \cdots$ & - & ميكروگرم بر كرم كراتينين & ترانس ترانس موكونيك اسيد & متابوليت ادرارى \\
\hline N/VVV & $\Gamma / \Lambda) \Lambda$ & זN/rq & $.1 \cdot 19$ & - & $r$. & بخش در ميليون & تولوئن & آلاينده \\
\hline$\cdot / \Delta V V$ & - IATA & $r / \cdots \Delta$ & $.1 \cdot 14$ & $1 / 9$ & - & كرم بر كرم كراتينين & هييوريك اسيد & متابوليت ادرارى \\
\hline gITFF & $r / . r k$ & $r \Delta / \cdot 1$ & $\cdot / \cdot 1$ & - & $r \cdot$ & بخش در ميليون & اتيلبنزن & آلاينده \\
\hline .1 .49 & .1 .48 &.$/ 1 \vee \Delta$ & .1 .11 & $\cdot / 1 \Delta$ & - & كرم بر كرم كراتينين & فنيل كلى اكزاليك اسيد & متابوليت ادرارى \\
\hline$V / .99$ & $r / T \Delta V$ & $r r / \Delta \wedge q$ &.$/ \cdot r \Delta$ & - & $1 \ldots$ & بخش در ميليون & ارتوَزيلن & آلاينده \\
\hline.$/ 4 V T$ & . IFVD & $\langle/ \cdot F|$ & $\cdot / 1 \cdot r$ & $1 / 0$ & - & كرم بر كرم كراتينين & r متيل هييوريك اسيد & متابوليت ادرارى \\
\hline$V 1.99$ & $r / T \Delta V$ & $r r / \Delta \wedge q$ & $.1 \cdot r \Delta$ & - & $1 .$. & بخش در ميليون & متاگزيلن & آلاينده \\
\hline.$/ 4 V T$ & - IFVD & $\langle/ \cdot F|$ & $\cdot / 1 \cdot r$ & $1 / \Delta$ & - & كرم بر كرم كراتينين & r متيل هييوريك اسيد & متابوليت ادرارى \\
\hline$F / F \cdot r$ & $r / \cdot 10$ & $\mid F / q F V$ &.$/ \cdot r_{\Delta}$ & - & $1 \cdots$ & بخش در ميليون & ياراززيلن & آلاينده \\
\hline و צس/. & $\cdot \pi v e$ & $1 / 4 \vee \Delta$ & $.1 \cdot 10$ & $1 / 0$ & - & كرم بر كرم كراتينين & f أ متيل هييوريك اسيد & متابوليت ادرارى \\
\hline
\end{tabular}

جدول با: مقايسه ميانكَين ميزان غلظت تركيبات BTEXs و متابوليت ادرارى آنها با حدود مجاز

\begin{tabular}{|c|c|c|c|}
\hline حد مجاز & >حد مجاز & كحد مجاز & نام آلاينده \\
\hline ه/ • بخش در ميليون & 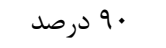 & • إ درصد & بنزن \\
\hline • • له ميكرو كرم بر ترم كراتينين & ج ج درصد & • ا ل درصد & ترانس ترانس موكونيك اسيد \\
\hline r r بخش در ميليون & 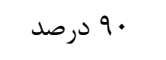 & ل الم لمرصد & 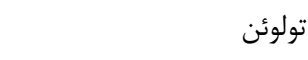 \\
\hline ع/ آرم بر ترم كراتينين & ج ا9 درصد & ل ال درصد & هييوريك اسيد \\
\hline r r بخش در ميليون & ا & F & اتيلبنزن \\
\hline ه | • • ترم بر گرم كراتينين & 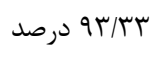 & 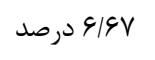 & فنيل كلى اگزاليك اسيد \\
\hline · · ل بخش در ميليون & 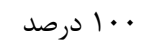 & • • • • درصد & ارتوزَيلن \\
\hline الهرم بر كرم كراتينين & س مس/rq درصد & 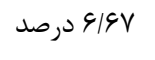 & r متيل هييوريك اسيد \\
\hline . · بخش در ميليون & ل & | • • • درصد & 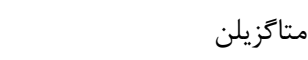 \\
\hline ه/ ا گرم بر گرم كراتينين & س ז/זף درصد & | & r متيل هييوريك اسيد \\
\hline · · إخش در ميليون & ل & | • • • درصد & 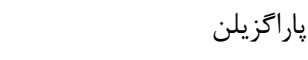 \\
\hline ه/ آرم بر ترم كراتينين & ل · ل إ درصد & • • • • درصد & F Fتيل هييوريك اسيد \\
\hline
\end{tabular}

اسيد ادرارى نشاندهنده ارتباط خطى، مستقيم و معنادارى بين

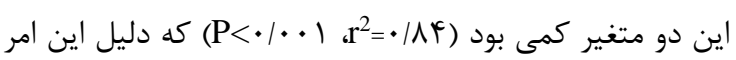

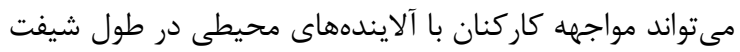

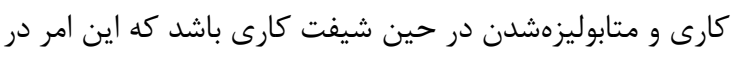

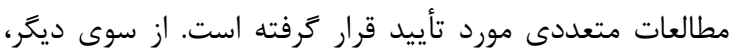

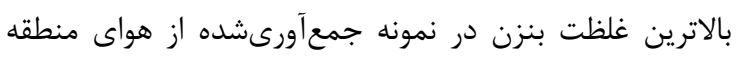

نتايجنشان دادند كه ميانگين غلظت BTEXs و متابوليتهاى

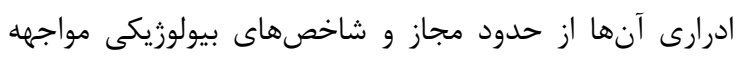

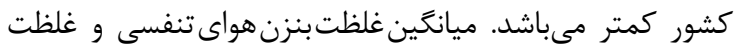

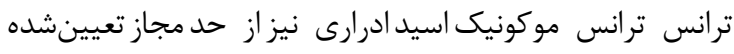

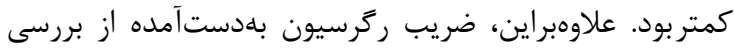

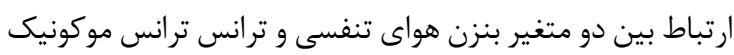



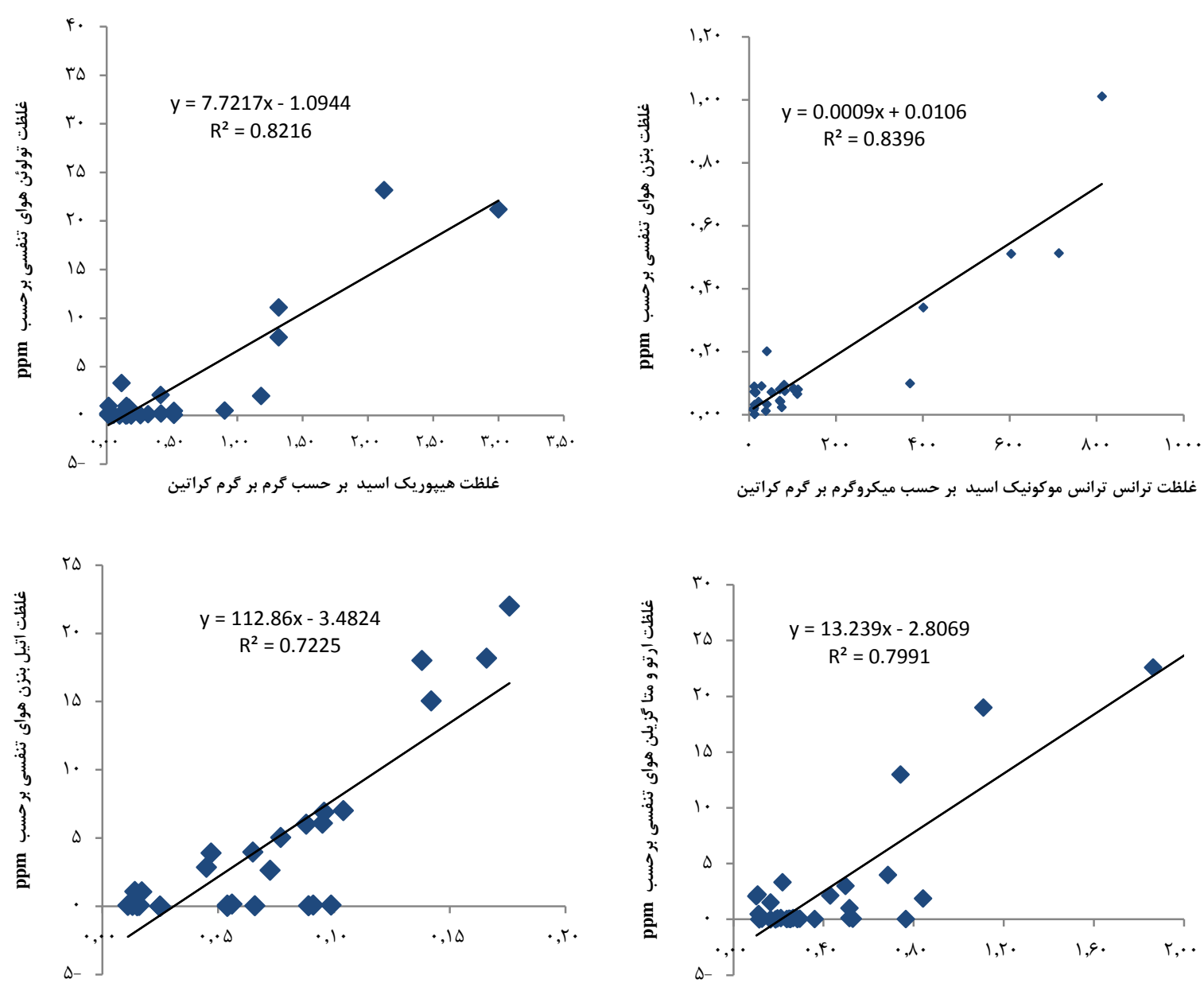

غلظت فنيل كلى اتزاليك اسيد بر حسب كرم بر كرم كراتين

غلظت r.T.Tتيل هييوريك اسيد بر حسب كرم بر كرم كراتين

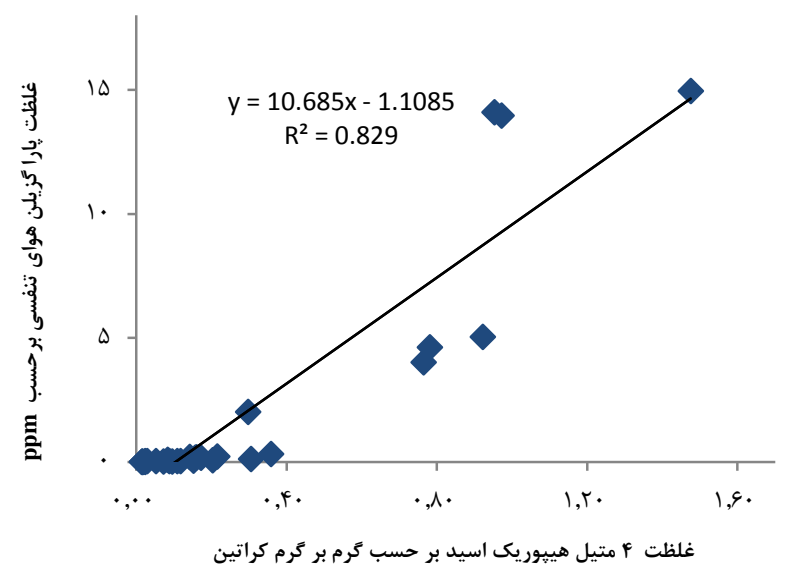

نمودار ا: منحنى ركرسيون ارتباط غلظت بنزن، تولوئن، اتيلبنزن و ارتو، متا و ياراگزيلن با متابوليتهاى ادرارى

توسط مركز سلامت محيط و كار كشور بيشتر مىباشد. در

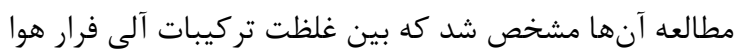

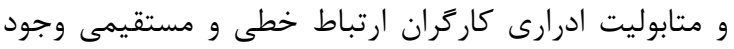
دارد [19].

در مطالعه Carrieri و همكاران كه در سال • • • ب در ارتباط با وج كارگر شاغل در صنعت يتروشيمى ايتاليا صورت كرفت نيز نشان داده شد كه ميانگين غلظت بنزن هواى تنفسى و

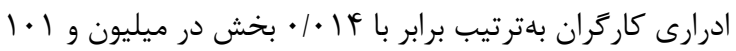

تنفسى كاركنان مربوط به متصدى انبار مواد شيميايى با

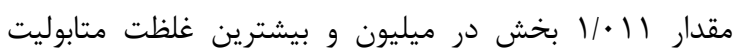

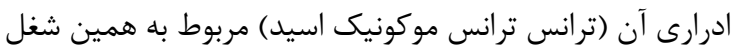

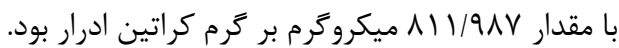

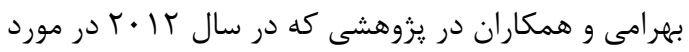

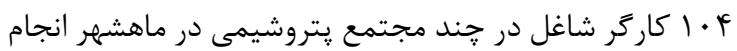

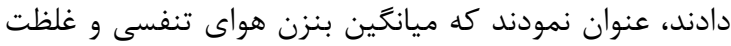

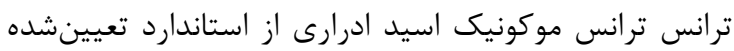


انجامدادند،به اين مهم دست يافتند كه مواجهه در غلظت ؟ \& • تا

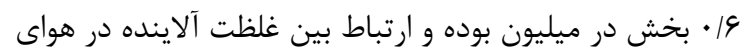

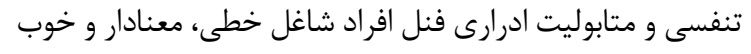

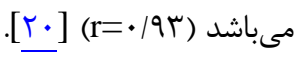

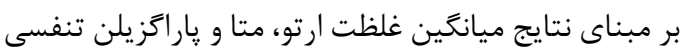

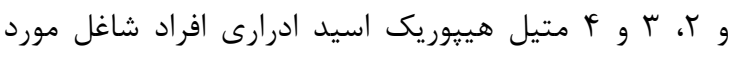

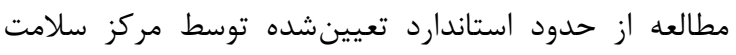

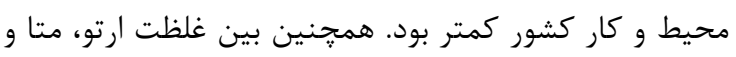

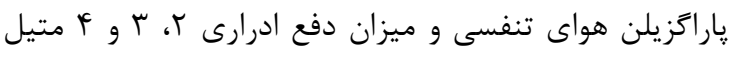

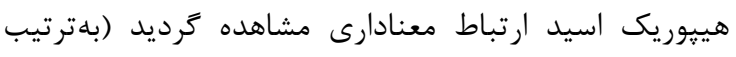

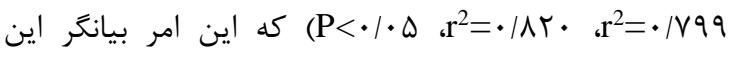

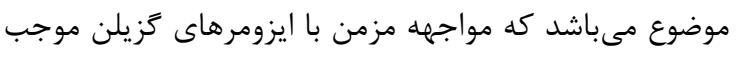

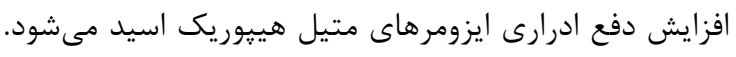

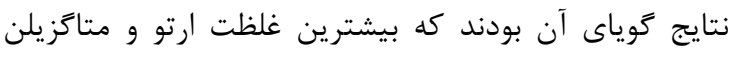

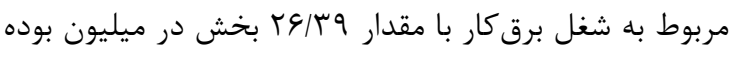

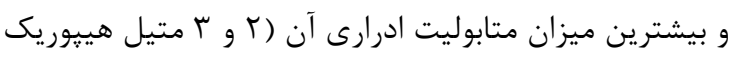

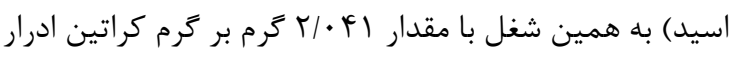

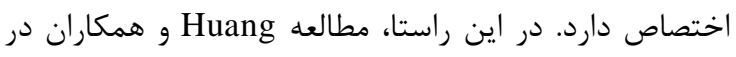

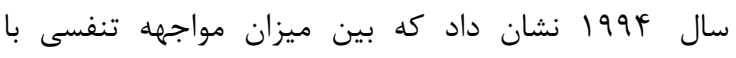

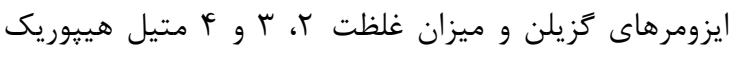

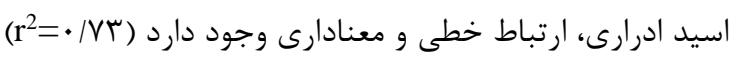

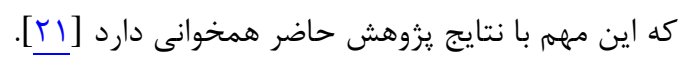

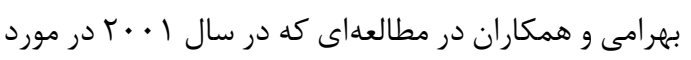

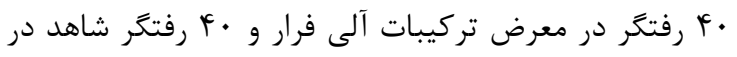

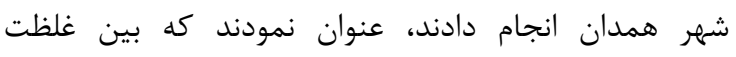

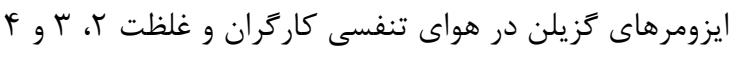

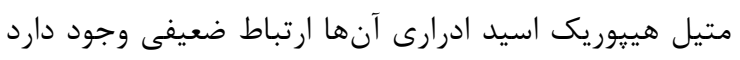

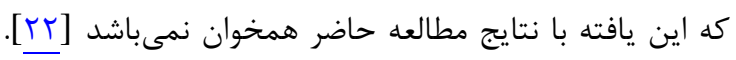

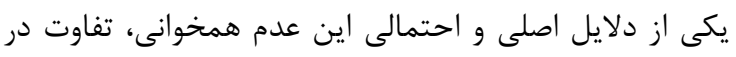

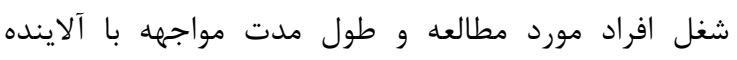
مى باشد. از سوى ديخر، با بررسى وضعيت انتشار آلايندها مشخص

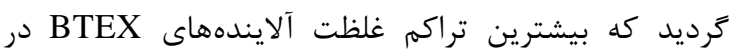

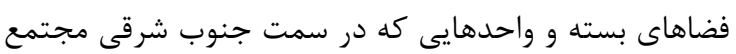

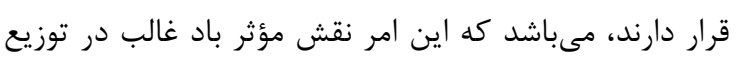

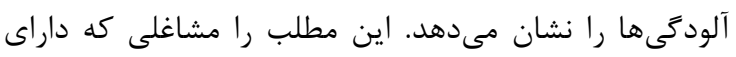

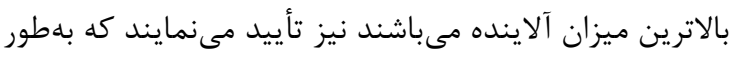

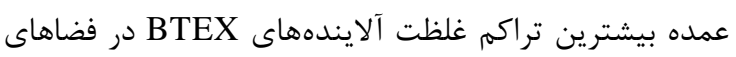

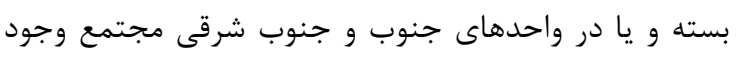

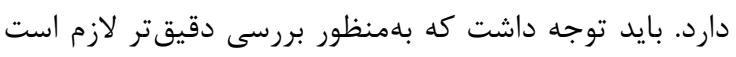

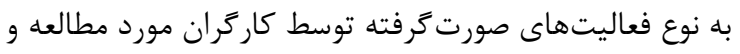

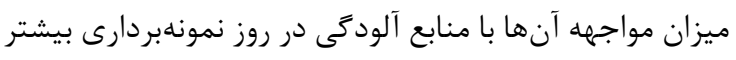
توجه گردد. با توجه به اهميت تركيبات سرطانزا در سطوح پايين
ميكروگرم بر گرم كراتينين مىباشد كه اين مقادير از حد مجاز

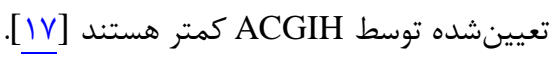

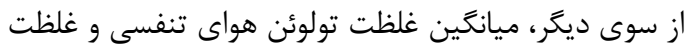

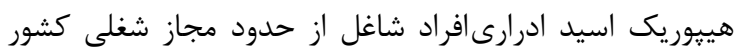

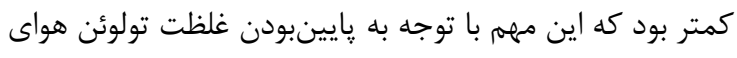

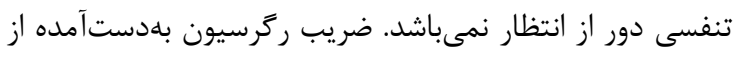

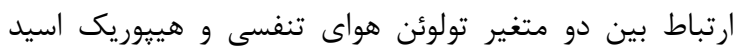

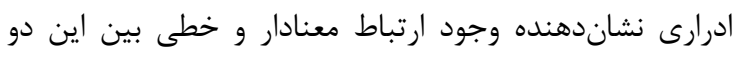

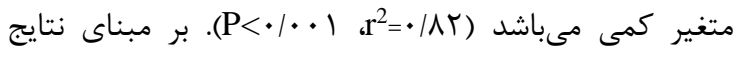

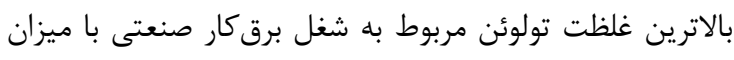

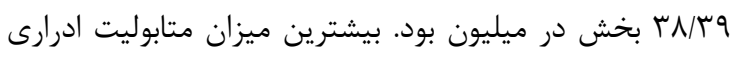

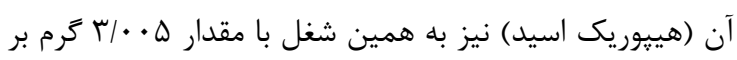
كرم كراتين ادرار اختصاص داشت.

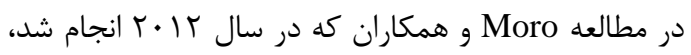
مشخص گرديد كه در مواجهه با مقادير بايين تولوئن، بين تولوئن

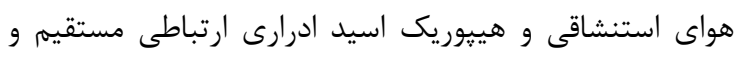

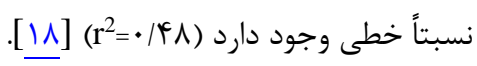
Angerer ارتباط با سب كاركر شاغل در صنايع شيميايى انجام دادند، عنوان نمودند كه بين غلظت تولوئن هواى استنشاقى و هييوريك اسيد

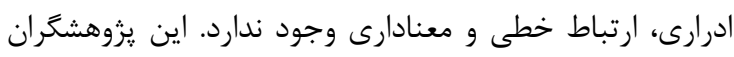

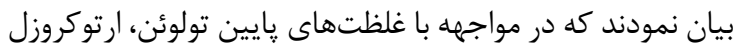

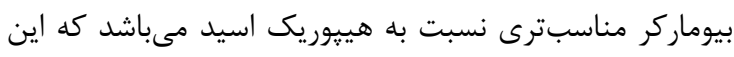

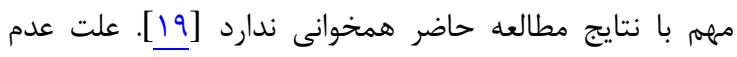

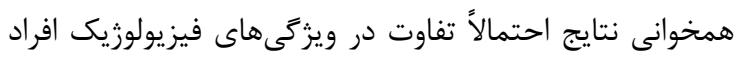

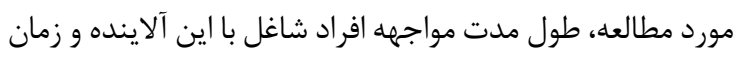
نمونهبردارى مىباشد. در يروهش حاضر ميانگين غلظت اتيلبنزن تنفسى و فنيل

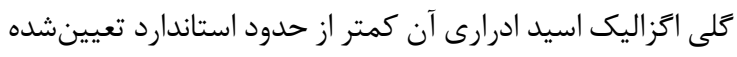

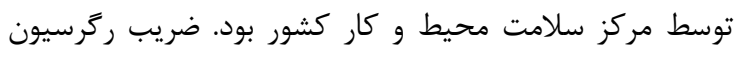

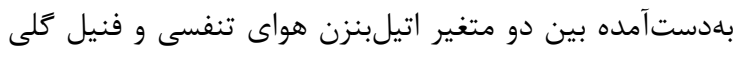

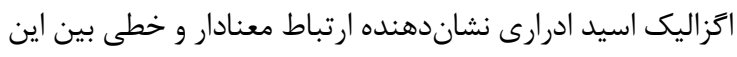

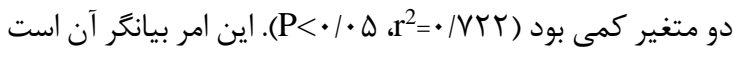

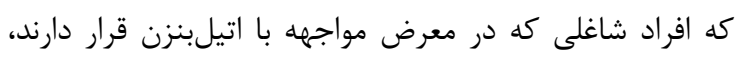

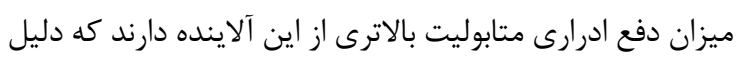

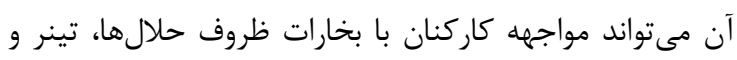

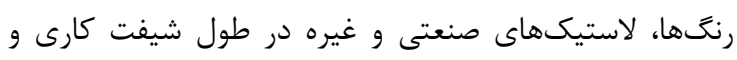

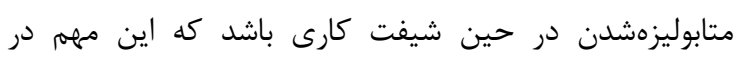

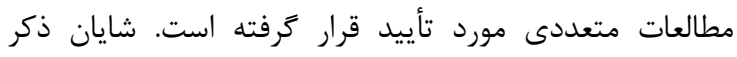

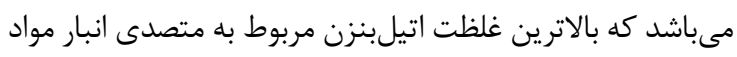

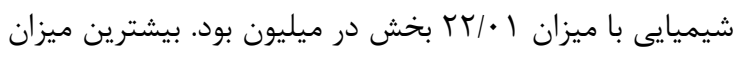

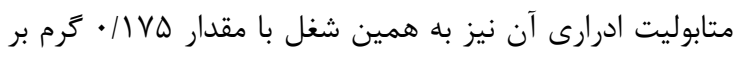

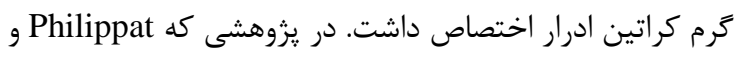

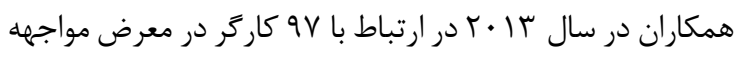




$$
\text { كار و مواجهه افراد شاغل برداشت [سب]. }
$$

\section{نتيجه كيرى}

نتايج اين بزوهش نشان دادند كه ميانكَين غلظت آلايندههاى

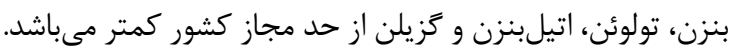

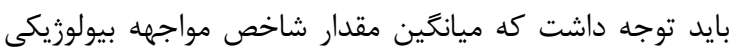

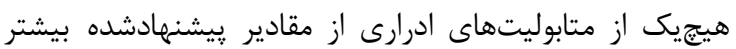

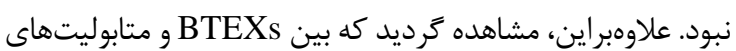

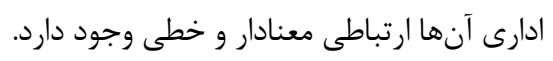

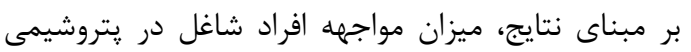

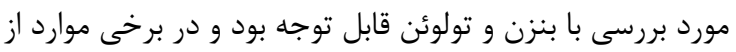

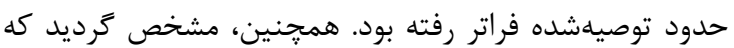

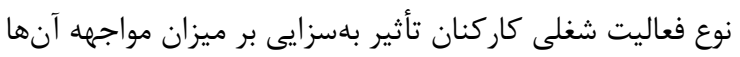

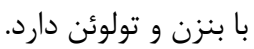

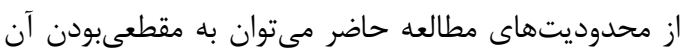

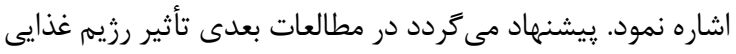

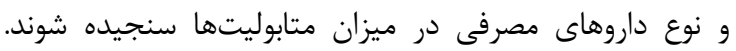

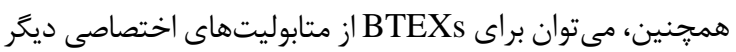
و و يا از دو متابوليت استفاده نمود.

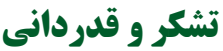

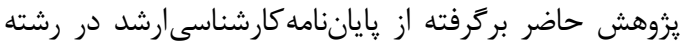

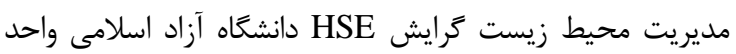
علوم و تحقيقات تهران مى باشد. بدينوسيله يزوهشكَران از همكارى

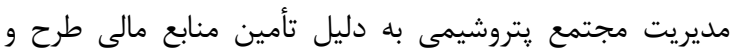

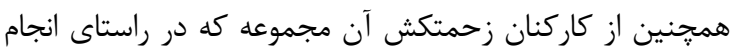

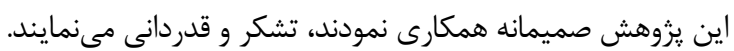

\section{REFERENCES}

1. Yadav JS, Reddy CA. Degradation of benzene, toluene, ethylbenzene, and xylenes (BTEX) by the lignin-degrading basidiomycete Phanerochaete chrysosporium. Appl Environ Microbiol. 1993;59(3):756-62. PMID: 8481002

2. Thepanondh S, Varoonphan J, Sarutichart P, Makkasap T. Airborne volatile organic compounds and their potential health impact on the vicinity of petrochemical industrial complex. Water Air Soil Pollut. 2011;214(1):83-92.

3. Health Center of Environment and Occupation. Chemical hazards guideline. Tehran: University of Tehran; 2012.

4. Bahrami A, Zare Sakhvidi MJ. Engineering, particle control methods. Tehran: Fanavaran; 2011. [Persian]

5. Al Zabadi H, Ferrari L, Sari-Minodier I, Kerautret MA, Tiberguent A, Paris C, et al. Integrated exposure assessment of sewage workers to genotoxicants: an urinary biomarker approach and oxidative stress evaluation. Environ Health. 2011;10(1):23. PMID: 21435260 DOI: 10.1186/1476-069X$\underline{10-23}$

6. National Toxicology Program. 12th Report on Carcinogens. North Carolina: U.S. Department of Health and Human Services, Public Health Service, National Toxicology Program; 2011.

7. Moradpour Z, Bahrami A, Sultanian A, Shahna FG, Negahban AR. Seasonal comparison of emissions of volatile organic compounds in the chemical industry based on oil during the years 2013 and 2014. Iran Occup Health J.
مواجهه در مدت زمان طولانى، راهكارهاى مديريتى و كنترلى

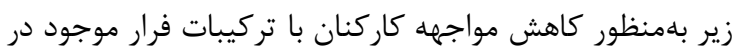

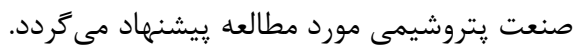

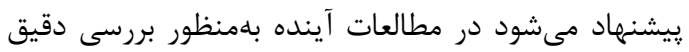

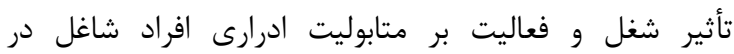

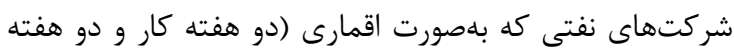

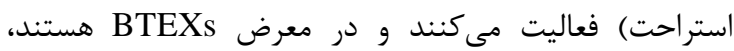

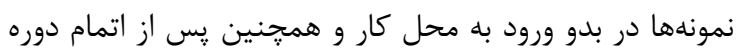

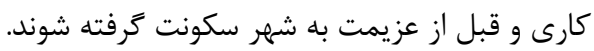
علاوهبراين، براى كار كاهها و فضاهاى بسته (از جمله اندان انبارهاى

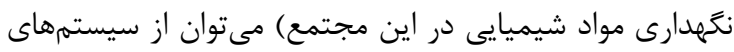

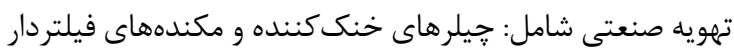

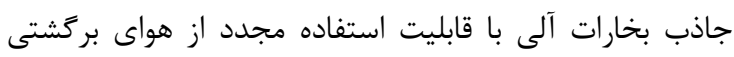

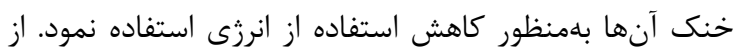

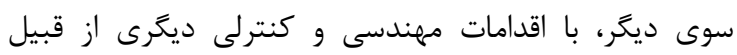

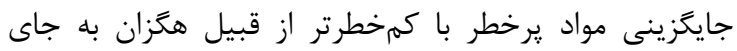

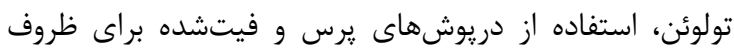

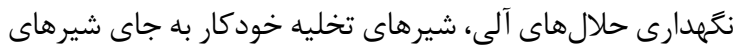

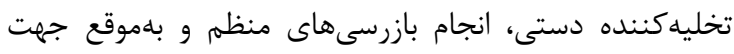

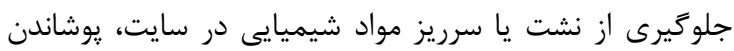

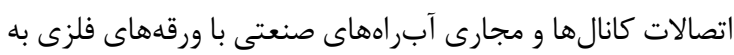

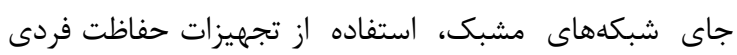

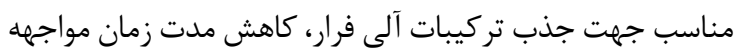

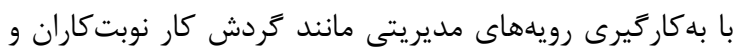

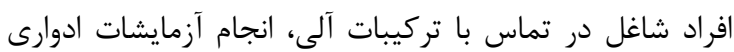

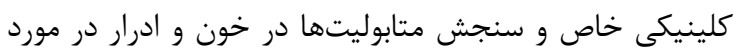
واحدها و مشاغل با ريسك بالا در كنار معاينات ادوارى ساليانيانه

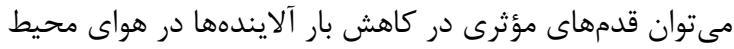

2015;11(6):55-63. [Persian]

8. Assary MJ. Guideline on the biological survey of the workplace, health and environment center. Hamedan: Daneshju; 2016. [Persian]

9. Lam PK, Gray JS. The use of biomarkers in environmental monitoring programmes. Marine Pollut Bull. 2003; 46(2):182-86. DOI: 10.1016/S0025-326X(02)00449-6

10. Keramati A, Nabizadeh Nodehi R, Rezaei Kalantary R, Nazmara S, Zahedi A, Azari A. TVOCs and BTEX Concentrations in the Air of South Pars Special Economic Energy Zone. J Mazandaran Univ Med Sci. 2016;26(133): 236-44. [Persian]

11. NIOSH 2549. NIOSH manual of analytical methods: hydrocarbons and aromatic. $4^{\text {th }}$ ed. New York: National Institute for Occupational Safety and Health; 2003. P. 1-6.

12. NIOSH 1501. NIOSH manual of analytical methods: hydrocarbons and aromatic. $4^{\text {th }}$ ed. New York: National Institute for Occupational Safety and Health; 2003. P. 1-7.

13. Na K, Kim YP, Moon KC, Moon I, Fung K. Concentrations of volatile organic compounds in an industrial area of Korea. Atmos Environ. 2001;35(15):2747-56. DOI: 10.1016/S13522310(00)00313-7

14. Cetin E, Odabasi M, Seyfioglu R. Ambient volatile organic compound (VOC) concentrations around a petrochemical complex and a petroleum refinery. Sci Total Environ. 2003;312(1-2):103-12. PMID: 12873403 DOI: 10.1016/ 
S0048-9697(03)00197-9

15. Rahimpoor R, Bahrami AR, Ghorbani F, Assari MJ, Negahban AR, Rahimnejad S, et al. Evaluation of urinary metabolites of volatile organic compounds and some related factors in petrochemical industry workers. $J$ Mazandaran Univ Med Sci. 2014;24(116):119-31. [Persian]

16. Rahimpoor R, Bahrami AR, Ghorbani F, Assari MJ, Negahban AR, Rahimnejad S, et al. Evaluation of urinary metabolites of volatile organic compounds and some related factors in petrochemical industry workers. $J$ Mazandaran Univ Med Sci. 2014;24(116):119-31. [Persian]

17. Carrieri M, Tranfo G, Pigini D, Paci E, Salamon F, Scapellato ML, et al. Correlation between environmental and biological monitoring of exposure to benzene in petrochemical industry operators. Toxicol Lett. 2010;192(1):17-21. PMID: 19628029 DOI: 10.1016/j.toxlet.2009.07.015

18. Moro AM, Brucker N, Charão M, Bulcão R, Freitas F, Baierle $\mathrm{M}$, et al. Evaluation of genotoxicity and oxidative damage in painters exposed to low levels of toluene. Mutat Res. 2012;746(1):42-8. PMID: 22405974 DOI: 10.1016/j. mrgentox.2012.02.007

19. Angerer J, Kramer A, Occupational chronic exposure solvents. XVI. Ambient and monitoring of workers exposed to toluene. Int Arch Environ Health. 1997;69(2):91-6. PMID: $\underline{9001914}$

20. Philippat C, Wolff MS, Calafat AM, Ye X, Bausell R, Meadows $\mathrm{M}$, et al. Prenatal exposure to environmental phenols: concentrations in amniotic fluid and variability in urinary concentrations during pregnancy. Environ Health Perspect. 2013;121(10):1225-31. PMID: 23942273 DOI: 10.1289/ehp.1206335

21. Huang. MY, Jin C, Liu Y T, Li B H, Qu QS, Uchida Y, et al. Exposure of workers to a mixture of toluene and xylenes. I. Metabolism. Occup Environ Med. 1994;51(1):42-6. PMID: 8124462

22. Bahrami A, Mahjub H, Asari M. Biological evaluation of Hippuric Acid concentration from metabolite of Toluene in urine of gas stations workers. J Qazvin Univ Med Sci. 2001;18:17-21. [Persian]

23. Muzenda E. Pre-treatment methods in the abatement of volatile organic compounds: a discussion. International Conference on Nanotechnology and Chemical Engineering, Bangkok, Thailand; 2012. 